or dietary history. She was adopted as a child and had no known family.

On general examination, she had lax skin blue sclera, and paper thin scars on forehead and shins. She was hypermobile and had bilateral pes planus. On questioning she said that she bruised easily, was double jointed and suffered from rectal prolapse. She was tender on the lumbar spine and the neurological examination in the lower limb was normal. Haematological and radiological investigations excluded myeloma or other malignant deposits.

A diagnosis of EDS type 2 was made. She underwent bone densitometry examination by dual energy $x$ ray absorptiometry which revealed $\mathrm{Z}$ scores of $-1 \cdot 21$ ( $\mathrm{T}$ score $-2 \cdot 69$ ) in the lumbar spine and $-1 \cdot 88$ ( $T$ score $-3 \cdot 55$ ) in the femoral neck. She was treated with analgesics and hydrotherapy and commenced hormone replacement therapy (HRT). Over the next four years, she consistently gained bone density at the lumbar spine, though after the initial gains HRT failed to maintain the bone mineral density (BMD) at the femoral neck (fig). Her backache has remained under control and she has had no new fractures.

In the past three years we have seen six other patients with EDS: four females aged 16-62 and two males aged 55 and 70 . None of them was known to have EDS; they were referred by their general practitioner for assessment of bone densitometry at their own request. Detailed history failed to identify any predisposing factors for osteoporosis and diagnoses of EDS were made for the first time as a result of clinical characteristics. All the patients had low BMD in either the lumbar spine or the femoral neck (table).

For the seven patients taken together, the average $\mathrm{Z}$ score was $-1 \cdot 4$ ( $\mathrm{T}$ score $-2 \cdot 26$ ) at

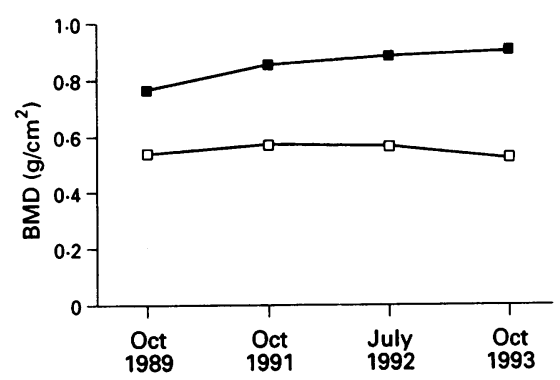

Patient with Ehlers Danlos Syndrome treated with HRT. Changes in bone density at the spine $(L 1,2,3)$ (a) and femoral neck (प) over four years. the lumbar spine and -1.83 ( T score $-3 \cdot 2$ ) at the femoral neck.

The genetic defects in the most common forms of EDS (types 1, 2, and 3) are as yet unknown, but in some forms of EDS the exact molecular pathology has been identified and includes hydroxylysine deficiency in EDS type 6, and defects in the synthesis and processing of types 1 and 3 collagens in EDS types 7 and $4 .^{5}$ Theories of mineralisation of the organic matrix of bone suggest that normal quality collagen is required to form normally mineralised bone. Histomorphometric and electron microscope studies support this theory and have shown that the defective collagen fibrils in OI may be nonmineralised or may contain crystals of hydroxyapatite that are irregularly arranged. ${ }^{6}$ We hypothesise that abnormality of the collagen framework in EDS leads to faulty deposition of bone mineral, with resultant decreased bone mass.

In a period of four years, the patient with EDS who received HRT showed improved spinal BMD, but lost BMD in the femoral neck. We previously found that HRT was not effective in maintaining bone mass in the lumbar spine in two of three postmenopausal female patients with OI. ${ }^{7}$ With so few subjects, it is impossible to draw any conclusions as to the effective therapy for treating osteoporosis in patients with heritable connective tissue diseases. Our results suggest, however, that careful monitoring by regular bone densitometry is invaluable in the assessment of therapy in these patients.

Ehlers Danlos Syndrome should be considered when assessing patients for presumed postmenopausal osteoporosis. The disorder may be missed earlier and present for the first time in later life as "osteoporotic fractures". The response to osteoporosis therapy in heritable connective tissue diseases can be unpredictable because of underlying collagen abnormalities and these patients therefore need careful monitoring.

A A DEODHAR A D WOOLF Duke of Cornwall Rheumatology Uni Royal Cornwall Hospital (City) Royal Cornwall Hospital (City)
Truro TR1 2HZ, United Kingdom

Correspondence to: Dr Deodhar.

1 Marini J C. Heritable collagen disorders. In Klippel J H, Dieppe P A eds. Rheumatology. St Louis: Mosby, 1993; 7: 44.1-8.

2 Rowe D W. Osteogenesis imperfecta. In: Heersche J N M, Kanis J A, eds. Bone and Heersche J N M, Kanis J A, eds. Bone and
mineral research, Vol 7. Amsterdam: Elsevier, 1990: 209-41.

Bone densitometry studies in seven patients with Ehlers Danlos syndrome (EDS): $Z$ and T scores of lumbar spine and femoral neck

\begin{tabular}{|c|c|c|c|c|c|c|}
\hline \multirow{2}{*}{$\begin{array}{l}\text { Patient } \\
\text { (age, sex) }\end{array}$} & \multirow{2}{*}{$\begin{array}{l}\text { EDS } \\
\text { type }\end{array}$} & \multirow[t]{2}{*}{ Clinical features } & \multicolumn{2}{|l|}{$Z$ score } & \multicolumn{2}{|l|}{$T$ score } \\
\hline & & & Spine & Hip & Spine & Hip \\
\hline $\begin{array}{l}53 \mathrm{~F} \\
\text { (PM } 2 \text { yr) }\end{array}$ & 2 & $\begin{array}{l}\text { Loose skin; hypermobility; easy } \\
\text { bruising; uterine prolapse; } \\
\text { spontaneous subconjuctival bleed }\end{array}$ & $-0 \cdot 22$ & $-1 \cdot 18$ & $-1 \cdot 18$ & $-2 \cdot 37$ \\
\hline $\begin{array}{l}16 \mathrm{~F} \text { (daughter } \\
\text { of above) }\end{array}$ & 2 & $\begin{array}{l}\text { Easy bruising; clicking of } \\
\text { joints; bluish sclera }\end{array}$ & $-1 \cdot 08$ & ND & $-1 \cdot 41$ & ND \\
\hline (PM $17 \mathrm{yr})$ & 2 & $\begin{array}{l}\text { Loose skin; Colles' fracture age } 51 \text {; } \\
\text { fracture of neck of femur age } 61\end{array}$ & $-1 \cdot 15$ & $-1 \cdot 48$ & $-2 \cdot 67$ & $-3 \cdot 2$ \\
\hline $44 \mathrm{~F}$ & 3 & $\begin{array}{l}\text { Hypermobility; knee effusions; } \\
\text { spontaneous subconjunctival bleed; } \\
\text { thin, loose skin }\end{array}$ & $-0 \cdot 35$ & $-1 \cdot 41$ & $-0 \cdot 76$ & $-2 \cdot 06$ \\
\hline $\begin{array}{l}65 \mathrm{~F}+ \\
(\mathrm{PM} 11 \mathrm{yr})\end{array}$ & 2 & $\begin{array}{l}\text { Loose skin; blue sclera; easy bruising; } \\
\text { rectal prolapse; fracture of L2 }\end{array}$ & $-1 \cdot 21$ & $-1 \cdot 88$ & $-2 \cdot 69$ & $-3 \cdot 55$ \\
\hline $70 \mathrm{M}$ & 2 & $\begin{array}{l}\text { Thin, lax skin on hands, feet, elbows, } \\
\text { and knees; easy bruising }\end{array}$ & $-2 \cdot 69$ & $-2 \cdot 74$ & $-3 \cdot 6$ & $-4 \cdot 71$ \\
\hline $55 M$ & 2 & $\begin{array}{l}\text { Loose skin; high arched palate; } \\
\text { tall marphanoid features }\end{array}$ & -3.05 & $-2 \cdot 33$ & $-3 \cdot 55$ & $-3 \cdot 71$ \\
\hline
\end{tabular}

†Patient described in text. $\mathrm{PM}=$ postmenopause; $\mathrm{ND}=$ hip scan not done.

3 Biering A, Iverson T. Osteogenesis imperfecta associated with Ehlers Danlos syndrome. Acto Paediatr 1955; 44: 279-85.

4 Sippola M, Kaffe S, Propock D J. A heterogenous defect for structurally altered pro-alfa 2 chain of type 1 in procollgen in a pro-alfa2 chain of type 1 in procollgen in a mild variant of osteogenesis imperfecta. The altered structure decreases the thermal stability of procollagen and makes it resistan to procollagen $\mathrm{N}$ proteinase. $\mathcal{F}$ Biol Chem 1984; 259: 14094-15100.

5 Pope F M. Molecular abnormalities of collagen. In: Maddison P J, Isenberg D A, Woo P, Glass D N, eds. Oxford textbook of rheumatology. Oxford: Oxford Medical Publications, 1993; 204-32.

6 Cassella J P, Yousuf Ali S. Abnormal collagen and mineral formation in osteogenesis imperfecta. Bone Miner 1992; 17: 123-8.

7 Deodhar A A, Brabyn J, Woolf A D. Monitoring osteogenesis imperfecta by bone densitometry. In: Proceedings of the Fifth Inter national Conference on Osteogenesis Imperfecta. Oxford: University of Oxford, 1993; 52-3.

\section{Remission of nephrotic syndrome in a patient with renal amyloidosis associated with Takayasu's arteritis after treatment with dimethylsulphoxide}

Amyloidosis is a chronic infiltrative disorder characterised by the presence of extracellular deposits of insoluble proteins of unknown nature. Renal involvement generally carries a poor prognosis in patients with secondary amyloidosis, who usually display severe proteinuria, nephrotic syndrome and progressive renal failure; uraemia is the major cause of death in this group. ${ }^{1}$ There is as yet no accepted treatment for amyloidosis and the patient's life expectancy is short. ${ }^{2} \mathrm{We}$ present a patient with renal amyloidosis associated with Takayasu's arteritis (TA) (aortitis syndrome) who demonstrated a favourable clinical course.

This 29 year old woman was admitted to our hospital in April 1981 with nephrotic syndrome. Her history revealed that, seven years earlier, she had presented with fever, vertigo, and systolic hypertension. Stenosis of the abdominal aorta was noted. TA was diagnosed; the patient had received prednisolone $5 \mathrm{mg}$ daily since that time. There was no family hereditary disease including amyloidosis.

At admission in 1981, physical examination revealed a systolic heart murmur and murmurs in the neck, subclabicular area, and abdomen. Blood pressures taken in the right arm, left arm, right leg, and left leg were $158 / 40,164 / 40,110 / 40$ and $104 / 40 \mathrm{~mm} \mathrm{Hg}$, respectively. Laboratory data revealed massive proteinuria of $8.0 \mathrm{~g} /$ day. There was no haematuria and renal function was normal, with creatinine $0.56 \mathrm{mg} / \mathrm{dl}$, blood urea nitrogen $6.0 \mathrm{mg} / \mathrm{dl}$, and glomerular filtration rate $123.4 \mathrm{ml} / \mathrm{min}$. Serum albumin concentration was $2.3 \mathrm{~g} / \mathrm{dl}$ and total cholesterol concentration $289 \mathrm{mg} / \mathrm{dl}$; C reactive protein concentration was $>1 \mathrm{mg} / \mathrm{dl}$ and serum gamma globulin concentration $1.69 \mathrm{~g} / \mathrm{dl}$. The erythrocyte sedimentation rate (ESR) was $149 \mathrm{~mm} / \mathrm{h}$

Examination of tissue obtained at renal biopsy revealed varying degrees of amyloid deposition in the mesangial areas of all glomeruli. A few arterioles showed mild foca deposits of amyloid. The glomeruli and the interlobular artery were positively stained with Congo red and antibody to amyloid-A protein. Electron microscopy showed amyloid fibrils in the glomerular mesangium and subepithelial region. Deposition of amyloid was 


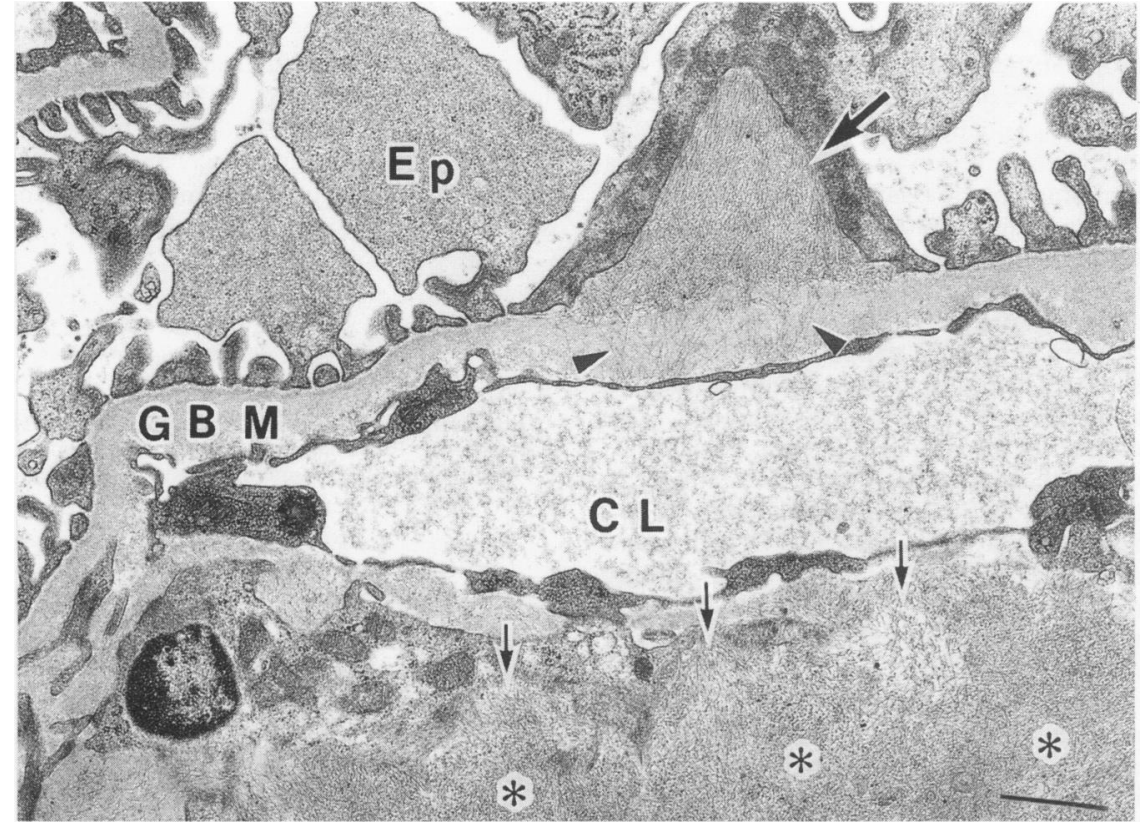

noted also in the salivary gland. The diagnosis was amyloidosis secondary to TA. The dose of prednisolone was increased to $15 \mathrm{mg}$ daily. Although inflammatory findings improved, the nephrotic syndrome persisted. In October 1981, oral administration of dimethylsulphoxide (DMSO) was started, at an initial dose of $1.5 \mathrm{~g} /$ day, increased gradually to $5.4 \mathrm{~g} /$ day over a period of four months. With the largest dose, there was a decrease in urinary protein to $2.4 \mathrm{~g} /$ day by January 1982, when the patient was discharged from hospital. Urinary excretion of protein subsequently decreased to less than $1 \mathrm{~g} /$ day by November 1982. At that time administration of DMSO was discontinued, but prednisolone was continued, at a dose of 5-10 mg/day.

The patient experienced a relapse of the nephrotic syndrome in April 1986. At that time, renal biopsy showed amyloid deposition that was quantitatively similar to that observed in the first biopsy specimen. Electron microscopy revealed deposition of amyloid mainly in the mesangial region and partly in the subepithelium (fig). As the TA was also active, the dose of prednisolone was increased to $40 \mathrm{mg} /$ day; DMSO was also reinstituted. This led to a gradual decrease in urinary protein until March 1987, when none could be detected and DMSO administration was stopped. The patient continued to receive prednisolone $7.5 \mathrm{mg}$ daily. Although some inflammatory findings persist $(0.81 \mathrm{mg} /$ $\mathrm{dl}$ of $\mathrm{C}$ reactive protein, ESR $20 \mathrm{~mm} / \mathrm{h}$ ) no proteinuria is currently present and renal function is normal (creatinine $0.61 \mathrm{mg} / \mathrm{dl}$ ). Thirteen years after the onset of amyloidosis, the patient is relatively well.

There have been occasional reports of patients with both TA and the nephrotic syndrome, most associated with amyloidosis; only six cases have been reported in the English literature. ${ }^{3}$

The course of renal amyloidosis is typically progressive. Once the nephrotic syndrome becomes established, or when azotaemia appears, the prognosis is poor: ${ }^{2}$ fewer than $10 \%$ of patients with the nephrotic syndrome survive as long as three years. ${ }^{4}$ However, remission has been achieved in patients with amyloidosis secondary to tuberculosis or burns, ${ }^{5}$ with resolution of the underlying chronic inflammation. Fritz et $a l^{6}$ described a patient with primary systemic amyloidosis who survived for 19 years after treatment with melphalan and prednisolone.

There is no satisfactory treatment for renal amyloidosis. Steroid administration is ineffective. ${ }^{7}$ We were able to induce remission of the nephrotic syndrome by a combination of a steroid with DMSO in a patient who was receiving the steroid treatment for her underlying TA, not for the amyloidosis. While prednisolone alone was ineffective for controlling the proteinuria, the addition of DMSO proved effective; its withdrawal led to a relapse of the nephrotic syndrome but readministration was again effective in controlling the nephrotic syndrome.

DMSO is an industrial solvent that was first used by Isobe and Ossermann for treating amyloidosis in mice. ${ }^{8}$ In this species, the agent produces partial or total disappearance of amyloidosis secondary to casein administration. Ravid et $a l^{9}$ reported the unequivocal improvement of renal function after three to six months of DMSO treatment in seven patients with secondary amyloidosis. Scheinberg et al ${ }^{10}$ also reported a beneficial effect of DMSO on renal function in patients with secondary amyloidosis at an early stage of renal involvement. The mechanism of action of DMSO on the organs affected by amyloidosis is not clear. Ravid's group ${ }^{9}$ speculated that its main effect may be anti-inflammatory, and that the improvement in renal function may result from the inhibition or regression of interstitial changes that accompany the deposition of renal amyloid. As DMSO is a potential scavenger of the hydroxyl radical, its efficacy may be related to its scavenging effect on active oxygen species. In our patient, DMSO not only improved her renal function, but also reduced the proteinuria associated with her secondary amyloidosis.

HIROFUMI MAKINO YOSHIO NAGAKE KAZUHARU MURAKAMI

SHUZO HIRAKAWA ZENSUKE OTA Third Department of Internal Medicine Okayama University Medical School 2-5-1 Shikata-Cho, Okayama 700, fapan

Correspondence to: Dr H Makino.
Electron micrograph of the second renal biopsy showing deposition of amyloid in the mesangial (*) and subepithelial (large arrow) regions. Note amyloid fibrils on the glomerular basement membrane (GBM) (arrow heads) and mesangial region (small arrows). Ep = epithelial cell; $C L=$ capillary lumen. Horizontal bar represents $1 \mathrm{\mu m}$.

1 Cohen A S. Amyloidosis. N Engl f Med 1967; 277: 522-30, 574-83, 628-38.

2 Kyle R A, Greipp P R. Amyloidosis (AL): clinical and laboratory features in 229 cases. Mayo Clin Proc 1983; 58: 665-83.

3 Mista S S, Prakash S, Argawal P L. Pulseless disease (Takayasu's syndrome). Am Heart $\mathcal{F}$ 1959; 57: 177-84.

4 Cohen A S, Ribinow A, Anderson J, et al. Survival of patients with primary (AZ) amyloidosis: colchicine-treated patients compared with cases seen in previous years (1961-1978). Am f Med 1987; 82: 1182-90.

5 Reinmann $\mathrm{H}$ A. Recovery from amyloidosis. FAMA 1935; 104: 1070-1.

6 Fritz D A, Luggen M E, Hess E V. Unusual longevity in primary systemic amyloidosis: a 19-year survivor. Am f Med 1989; 86: 245-8.

7 Maxwell M H, Adams D A, Goldman R. Corticosteroid therapy of amyloid nephrotic syndrome. Ann Intern Med 1964; 60: 539-55.

8 Isobe $T$. Ossermann $E$ F. Effects of dimethyl ulfoxide (DMSO) on Eence Jones prosulfoxide (DMSO) on Bence Jones proteins, amyloid fib and casein-induced amyloidosis. In: Wegelius O, Pasternak A, eds. Amyloidosis. New York: Academic Press, 1976: 247-57.

9 Ravid M, Shapira J, Lang R, Kedar I. Prolonged dimethylsulphoxide treatment in 13 patients with systemic amyloidosis. Ann Rheum Dis 1982; 41: 587-92.

10 Scheinberg M A, Pernambuco J C, Benson M D. DMSO and colchicine therapy in amyloidosis. Ann Rheum Dis 1984; 43: 421-3.

\section{Superficial migratory thrombophlebitis in a patient with reversible protein $\mathrm{C}$ deficiency and anticardiolipin antibodies}

Superficial migratory thrombophlebitis is a rare manifestation of secondary hypercoagulable states. It has been described in association with infectious diseases, in particular secondary syphilis, in addition to malignancies and vasculitic disorders such as Behçet's disease or thromboangiitis obliterans. ${ }^{1}$ We describe here the case of a patient with migratory superficial thrombophlebitis in which increased antiphospholipid antibody concentrations in plasma and a protein $C$ deficiency were found. The clinical symptoms and the pathological laboratory results were reversible by antibiotic treatment.

A 26 year old male medical student was referred to the rheumatology outpatient unit because of migratory arthritis and multiple superficial thrombophlebitis. He had been in good health until one year earlier, when he had worked for two months in a hospital in Namibia (Africa). Two months after his return to Germany he complained of red and painful nodules at the dorsum of both feet, which persisted for several months. After a further two months he developed migratory arthritis of the joints of the fingers and toes. A biopsy of a cutaneous nodule was performed which showed inflammatory infiltration of the wall of a thrombotic vein. The histology confirmed the clinical diagnosis of thrombophlebitis. The patient received topical therapy (venous compression, local heparin) but was referred to our clinic because of persistence of symptoms. 